\title{
T-Type Calcium Channels Contribute to Burst Firing in a Subpopulation of Medial Habenula Neurons
}

\author{
DCasey R. Vickstrom, Xiaojie Liu, Yuqi Zhang, Lianwei Mu, Thomas J. Kelly, Xudong Yan, \\ Meng-ming Hu, Shana T. Snarrenberg, and \Qing-song Liu
}

https://doi.org/10.1523/ENEURO.0201-20.2020

Department of Pharmacology and Toxicology, Medical College of Wisconsin, Milwaukee, WI 53226

\begin{abstract}
Action potential (AP) burst firing caused by the activation of low-voltage-activated T-type $\mathrm{Ca}^{2+}$ channels is a unique mode of neuronal firing. T-type channels have been implicated in diverse physiological and pathophysiological processes, including epilepsy, autism, and mood regulation, but the brain structures involved remain incompletely understood. The medial habenula $(\mathrm{MHb})$ is an epithalamic structure implicated in anxiety-like and withdrawal behavior. Previous studies have shown that $\mathrm{MHb}$ neurons fire tonic APs at a frequency of $\sim 2-$ $10 \mathrm{~Hz}$ or display depolarized low-amplitude membrane oscillations. Here, we report in C57BL/6J mice that a subpopulation of $\mathrm{MHb}$ neurons are capable of firing transient, high-frequency AP bursts mediated by T-type channels. Burst firing was observed following rebounding from hyperpolarizing current injections or during depolarization from hyperpolarized membrane potentials in $\sim 20 \%$ of $\mathrm{MHb}$ neurons. It was rarely observed at baseline but could be evoked in $\mathrm{MHb}$ neurons displaying different initial activity states. Further, we show that T-type channel mRNA, in particular $\mathrm{Ca}_{\mathrm{v}} 3.1$, is expressed in the $\mathrm{MHb}$ in both cholinergic and substance Pergic neurons. Pharmacological $\mathrm{Ca}_{\mathrm{v}} 3$ antagonism blocked both burst firing and evoked $\mathrm{Ca}^{2+}$ currents in $\mathrm{MHb}$ neurons. Additionally, we observed high-frequency AP doublet firing at sustained depolarized membrane potentials that was independent of T-type channels. Thus, there is a greater diversity of AP firing patterns in $\mathrm{MHb}$ neurons than previously identified, including T-type channel-mediated burst firing, which may uniquely contribute to behaviors with relevance to neuropsychiatric disease.
\end{abstract}

Key words: burst; calcium; habenula; T-type channel

\section{Significance Statement}

Previous studies have reported that medial habenula $(\mathrm{MHb})$ neurons solely fire tonic action potentials (APs) at $\sim 2-10 \mathrm{~Hz}$ or display depolarized low amplitude membrane oscillations. In contrast, we found that a subpopulation of $\mathrm{MHb}$ neurons fire high-frequency $\mathrm{AP}$ bursts that share the characteristics of T-type $\mathrm{Ca}^{2+}$ channel-mediated low threshold spikes and were blocked by pharmacological antagonism of T-type $\mathrm{Ca}^{2+}$ channels. T-type $\mathrm{Ca}^{2+}$ channel mRNA, especially $\mathrm{Ca}_{\mathrm{v}} 3.1$, is expressed in the $\mathrm{MHb}$ in both cholinergic and substance P-ergic neurons. T-type channel-independent AP doublets were also observed in $\mathrm{MHb}$ neurons at sustained depolarized membrane potentials. Thus, there is a greater diversity of AP firing patterns in $\mathrm{MHb}$ neurons than previously recognized, including T-type $\mathrm{Ca}^{2+}$ channel-mediated burst firing.

\section{Introduction}

Burst action potential (AP) firing mediated by the activation of low-voltage-activated T-type $\mathrm{Ca}^{2+}$ channels is a unique mode of neuronal activity that occurs in various

Received May 19, 2020; accepted July 6, 2020; First published July 27, 2020.

The authors declare no competing financial interests. neuronal populations, particularly in thalamic, septal, and sensory neurons (Perez-Reyes, 2003; Cheong and Shin, 2013; Lambert et al., 2014). This burst firing has been

Author contributions: C.R.V., X.L., and Q.-s.L. designed research; C.R.V., X.L., Y.Z., L.M., T.J.K., X.Y., M.-m.H., and S.T.S. performed research; C.R.V., X.L., Y.Z., L.M., T.J.K., X.Y., M.-m.H., S.T.S., and Q.-S.L. analyzed data; C.R.V. and Q.-s.L. wrote the paper. 
shown to mediate important physiological and pathophysiological processes, including the synchronization of the thalamocortical circuit and the generation of rhythmic neuronal activity during normal sleep (Huguenard and McCormick, 2007), spike-wave discharges in absence epilepsy (Huguenard and McCormick, 2007), and neuropathic pain (Bourinet et al., 2016). Additionally, mutations in T-type $\mathrm{Ca}^{2+}$ channel genes have been implicated in epilepsy, autism spectrum disorder, and schizophrenia (Weiss and Zamponi, 2020). There are three distinct Ttype $\mathrm{Ca}^{2+}$ channel genes: CACNA1G, CACNA1H, and CACNA1I, which encode the pore-forming $\alpha 1$ subunits known as $\mathrm{Ca}_{\mathrm{v}} 3.1, \mathrm{Ca}_{\mathrm{v}} 3.2$, and $\mathrm{Ca}_{\mathrm{v}} 3.3$, respectively (Perez-Reyes, 2003). In contrast to the other voltagegated $\mathrm{Ca}^{2+}$ channels, T-type $\mathrm{Ca}^{2+}$ channels have unique features, including low-voltage activation, rapid voltagedependent inactivation, and the generation of transient currents that can trigger a brief burst of high-frequency APs (Llinás and Jahnsen, 1982; Perez-Reyes, 2003; Cheong and Shin, 2013). As a large proportion of T-type $\mathrm{Ca}^{2+}$ channels are inactivated at typical resting membrane potentials $\left(V_{m}\right)$, neuron hyperpolarization can de-inactivate T-type $\mathrm{Ca}^{2+}$ channels and trigger a burst of APs, a phenomenon called "rebound bursting" (Llinás and Jahnsen, 1982; Perez-Reyes, 2003; Cheong and Shin, 2013). Burst firing can have unique functional consequences, including information encoding by enhancing signalto-noise ratio, facilitation of neuropeptide release, and increasing the reliability of synaptic transmission (Lisman, 1997; Schultz et al., 1997; van den Pol, 2012).

The habenula is a phylogenetically conserved epithalamic brain structure that is broadly classified into medial [medial habenula $(\mathrm{MHb})$ ] and lateral $(\mathrm{LHb})$ subnuclei (Sutherland, 1982; Antolin-Fontes et al., 2015; Boulos et al., 2017). The MHb regulates anxiety-like and depressive-like behavior (Görlich et al., 2013; Hsu et al., 2014, 2016), fear extinction (Soria-Gómez et al., 2015; Zhang et al., 2016), nicotine intake and withdrawal (Fowler et al., 2011; Frahm et al., 2015; Zhao-Shea et al., 2015; Tuesta et al., 2017), opioid withdrawal (Boulos et al., 2020), and stress responsivity in zebrafish (Agetsuma et al., 2010; Lee et al., 2010; Mathuru and Jesuthasan, 2013). There is well-documented evidence that neurons of the LHb are capable of firing bursts of APs mediated by T-type $\mathrm{Ca}^{2+}$ channel activation (Wilcox et al., 1988; Chang and Kim, 2004; Cui et al., 2018; Yang et al., 2018). Recent work has shown that LHb burst firing contributes to the

This work was supported by National Institutes of Health Grants MH115536 (to C.R.V.), MH121454, DA047269, and DA035217 (to Q.-s.L.). It was also partially funded through the Research and Education Initiative Fund, a component of the Advancing a Healthier Wisconsin endowment at the Medical College of Wisconsin. C.R.V. is a member of the Medical Scientist Training Program at Medical College of Wisconsin, which is partially supported by the National Institute of General Medical Sciences Training Grant T32-GM080202.

Correspondence should be addressed to Casey R. Vickstrom at cvickstrom@mcw.edu or Qing-song Liu at qsliu@mcw.edu.

https://doi.org/10.1523/ENEURO.0201-20.2020 Copyright @ 2020 Vickstrom et al.

This is an open-access article distributed under the terms of the Creative Commons Attribution 4.0 International license, which permits unrestricted use, distribution and reproduction in any medium provided that the original work is properly attributed. development of depressive-like behavior in rodents and that the rapid antidepressant effects of ketamine are mediated by blockade of LHb burst firing (Cui et al., 2018; Yang et al., 2018). In contrast, previous electrophysiological studies report that $\mathrm{MHb}$ neurons solely fire tonic, regular APs at a frequency between $\sim 2$ and $10 \mathrm{~Hz}$ (Kim and Chang, 2005; Kim and Chung, 2007; Görlich et al., 2013; Sakhi et al., 2014; Shih et al., 2014; Choi et al., 2016; Otsu et al., 2018; Weiss et al., 2018; Arvin et al., 2019; Ge et al., 2019).

In this study, we identified a subpopulation of $\mathrm{MHb}$ neurons that are capable of firing high-frequency AP bursts. Although only $\sim 7 \%$ of $\mathrm{MHb}$ neurons displayed burst firing at baseline, $\sim 20 \%$ displayed burst firing following membrane hyperpolarization or with depolarization from a hyperpolarized $V_{\mathrm{m}}$. Burst firing from a hyperpolarized $V_{\mathrm{m}}$ was blocked by the selective T-type $\mathrm{Ca}^{2+}$ channel antagonist Z944 (Tringham et al., 2012). We identified robust expression of $\mathrm{Ca}_{\mathrm{v}} 3.1 \mathrm{mRNA}$ predominantly in the lateral $\mathrm{MHb}$ using RNAscope in situ hybridization, which co-localized with tachykinin-1 (Tac1) and choline acetyltransferase (ChAT), markers which define neurons of the dorsal and ventral $\mathrm{MHb}$, respectively. These neurons have distinct anatomic projections to the interpeduncular nucleus and have unique roles in regulating anxiety-like and depressive-like behavior and nicotine dependence (Molas et al., 2017). Thus, MHb neuron burst firing, especially that mediated by T-type channel activation, is a previously unidentified mode of neuronal activity that could regulate diverse behaviors relevant to neuropsychiatric disorders.

\section{Materials and Methods}

\section{Animals}

All animal procedures were performed in accordance with the Medical College of Wisconsin animal care committee's regulations. C57BL/6J mice were given ad libitum access to food and water and housed four to five per cage in a temperature $\left(23 \pm 1^{\circ} \mathrm{C}\right)$ and humidity-controlled room (40-60\%) with a 14/10 h light/dark cycle. All experiments were performed on adult male or female C57BL/6J mice (8-10 weeks old). C57BL/6J mice were obtained from The Jackson Laboratory. Experiments were performed between zeitgeber time (ZT)8 and ZT14, where ZTO is lights on.

\section{Slice preparation and electrophysiology}

Mice were anesthetized by isoflurane inhalation and decapitated. The brain was trimmed and embedded in 3\% low-melting-point agarose, and coronal slices containing the $\mathrm{MHb}(200 \mu \mathrm{m}$ thick) were cut using a vibrating slicer (Leica VT1200s). Slices were prepared in a NMDG-based solution containing the following: $92 \mathrm{~mm} \mathrm{NMDG}, 2.5 \mathrm{~mm}$ $\mathrm{KCl}, 1.25 \mathrm{~mm} \mathrm{NaH}_{2} \mathrm{PO}_{4}, 26 \mathrm{~mm} \mathrm{NaHCO}, 20 \mathrm{~mm}$ HEPES, $25 \mathrm{~mm}$ glucose, $2 \mathrm{~mm}$ thiourea, $5 \mathrm{~mm}$ Na-ascorbate, $3 \mathrm{~mm}$ Na-pyruvate, $0.5 \mathrm{~mm} \mathrm{CaCl}_{2} \cdot 2 \mathrm{H}_{2} \mathrm{O}$, and $7 \mathrm{~mm} \mathrm{MgSO}_{4}(\mathrm{pH}$ 7.3-7.4 with $\mathrm{HCl}$ ). Artificial CSF (ACSF), containing the following: $119 \mathrm{~mm} \mathrm{NaCl}, 3 \mathrm{~mm} \mathrm{KCl}, 2 \mathrm{~mm} \mathrm{CaCl}, 1 \mathrm{~mm} \mathrm{MgCl}_{2}$, $1.25 \mathrm{~mm} \mathrm{NaH}_{2} \mathrm{PO}_{4}, 25 \mathrm{~mm} \mathrm{NaHCO}_{3}$, and $10 \mathrm{~mm}$ glucose, 
was gradually spiked-in to the NMDG-containing solution after slice cutting in 5-min intervals for a total of $20 \mathrm{~min}$ at room temperature, similar to a previously described approach (Ting et al., 2018). Some slices were cut in a sucrose-based solution containing the following: $68 \mathrm{~mm}$ sucrose, $78 \mathrm{~mm} \mathrm{NaCl}, 3 \mathrm{~mm} \mathrm{KCl}, 2 \mathrm{~mm} \mathrm{CaCl}_{2}$, $1 \mathrm{~mm} \mathrm{MgCl}, 1.25 \mathrm{~mm} \mathrm{NaH}_{2} \mathrm{PO}_{4}, 25 \mathrm{~mm} \mathrm{NaHCO}_{3}$, and $25 \mathrm{~mm}$ glucose. These slices were incubated in the same solution for 20 min after cutting. The slices were then allowed to recover for at least $1 \mathrm{~h}$ in ACSF. All solutions were saturated with $95 \% \mathrm{O}_{2}$ and $5 \% \mathrm{CO}_{2}$.

Whole-cell patch-clamp recordings were made using patch-clamp amplifiers (Multiclamp 700B) under infrared differential interference contrast (DIC) microscopy. Data acquisition and analysis were performed using DigiData 1550B digitizers and the analysis software pClamp 10.7 (Molecular Devices). Signals were filtered at $2 \mathrm{kHz}$ and sampled at $10 \mathrm{kHz}$. Recordings were performed in the presence of the AMPA receptor antagonist 6-cyano-7-nitroquinoxaline-2,3-dione disodium salt (CNQX; $10 \mu \mathrm{M}$ ) and $\mathrm{GABA}_{\mathrm{A}}$ receptor antagonist picrotoxin $(50 \mu \mathrm{M})$ unless otherwise stated. For before-and-after comparisons, the selective T-type $\mathrm{Ca}^{2+}$ channel antagonist Z944 $(3 \mu \mathrm{M})$, the NMDA receptor antagonists (RS)-3-(2-carboxypiperazin4-yl)-propyl-1-phosphonic acid (CPP; $5 \mu \mathrm{M})$ or $D-(-)-2-$ amino-5-phosphonopentanoic acid (AP-5; $50 \mu \mathrm{M}$ ), or CNQX (20 $\mu \mathrm{m})$ were bath perfused in ACSF in recordings where neurons fired apparent bursts, and current protocols that induced bursting before drug perfusion were repeated after drug perfusion. $\mathrm{Ca}^{2+}$ current recordings used two different voltage protocols to evoked $\mathrm{Ca}^{2+}$ currents. For determining the voltage dependence of activation, neurons were first held for $1 \mathrm{~s}$ at $-90 \mathrm{mV}$, followed by a $320-\mathrm{ms}$ step to progressively more depolarized holding potentials in 5-mV increments, beginning at $-90 \mathrm{mV}$ and finishing at $-30 \mathrm{mV}$, followed by return to $-90 \mathrm{mV}$ holding for $500 \mathrm{~ms}$. Neurons were held at $-70 \mathrm{mV}$ between sweeps. For determining the voltage dependence of inactivation, neurons were first held for $3.6 \mathrm{~s}$ at progressively more depolarized membrane potentials in $5-\mathrm{mV}$ increments, beginning at $-120 \mathrm{mV}$ and finishing at $-50 \mathrm{mV}$. After this initial holding potential, neurons were stepped to $-50 \mathrm{mV}$ for 320 , followed by holding at $-90 \mathrm{mV}$ for $1 \mathrm{~s}$. Neurons were held at $-70 \mathrm{mV}$ between sweeps. Glass pipettes (3-6 M $\Omega$ ) for current clamp recordings were filled with an internal solution containing the following: $140 \mathrm{mM}$ K-gluconate, $5 \mathrm{~mm} \mathrm{KCl,} 10 \mathrm{~mm}$ HEPES, 0.2 mm EGTA, 2 $\mathrm{mm} \mathrm{MgCl}_{2}, 4 \mathrm{~mm} \mathrm{Mg}-\mathrm{ATP}, 0.3 \mathrm{~mm} \mathrm{Na} \mathrm{N}_{2} \mathrm{GTP}$, and $10 \mathrm{~mm}$ $\mathrm{Na}_{2}$-phosphocreatine ( $\mathrm{pH} 7.2$ with $\left.\mathrm{KOH}\right)$. Glass pipettes for voltage clamp recordings of $\mathrm{Ca}^{2+}$ currents were filled with an internal solution containing the following: $135 \mathrm{~mm}$ tetramethyl ammonium (TMA)-OH, $10 \mathrm{~mm}$ EGTA, $2 \mathrm{~mm}$ $\mathrm{MgCl}_{2}$, and $40 \mathrm{~mm} \mathrm{HEPES}$, titrated to $\mathrm{pH} 7.2$ with hydrofluoric acid (HF; Todorovic and Lingle, 1998). Series resistance (15-30 M $\Omega$ ) was monitored throughout all recordings, and data were discarded if the resistance changed by $>20 \%$. Liquid junction potentials were not corrected for. All recordings were performed at $32 \pm 1^{\circ}$ C using an automatic temperature controller (Warner Instruments).

\section{RNAscope in situ hybridization}

Mice were deeply anesthetized with isoflurane and transcardially perfused with $0.1 \mathrm{~m}$ sodium PBS followed by $4 \%$ paraformaldehyde in $4 \%$ sucrose-PBS ( $\mathrm{pH} 7.4)$. After perfusion, the brain was removed and postfixed in the same fixative for $4 \mathrm{~h}$ at $4^{\circ} \mathrm{C}$ and was then dehydrated in increasing concentrations of sucrose $(20 \%$ and $30 \%)$ in $0.1 \mathrm{~m}$ PBS at $4^{\circ} \mathrm{C}$ and frozen on dry ice. Coronal $\mathrm{MHb}$ sections $(10 \mu \mathrm{m})$ were cut with a Leica cryostat and mounted on Superfrost Plus microscope slides (Fisher Scientific). Probes targeting the mRNA transcripts of $\mathrm{Ca}_{v} 3.1$ (target region: base pairs 1263-2886 of Mus musculus CACNA1G, NM_009783.3), $\mathrm{Ca}_{\mathrm{v}} 3.2$ (target region: base pairs 2287-4243 of $M$. musculus CACNA1H, NM_021415.4), Ca 3.3 (target region: base pairs 1259-2600 of $M$. musculus CACNA1I, NM_001044308.2), ChAT (target region: base pairs 1090-1952 of M. musculus ChAT, NM_009891.2), and Tac1 (target region: base pairs 20-1034 of $M$. musculus tachykinin 1, NM_009311.2) were designed by and purchased from Advanced Cell Diagnostics Inc. The experiment was conducted as per the manufacturer's instructions for the RNAscope Multiplex Fluorescent V2 Assay. Stained slides were mounted with ProLong Gold Antifade Mountant with DAPI (Invitrogen) and imaged on a Leica TCS SP8 confocal microscope. A probe targeting Bacilus subtilis protein DapB was used as a negative control, whereas probes targeting the ubiquitously expressed Polr2a, PPIB, and UBC served as positive controls.

\section{Statistics and data analysis}

Paired $t$ tests were used to analyze bursting before and after drug perfusion in current clamp recordings. Twoway ANOVA with repeated measures was used to analyze the effect of Z944 on evoked $\mathrm{Ca}^{2+}$ currents. Expression of T-type channel mRNA was analyzed by one-way ANOVA on ranks for $\mathrm{Ca}_{\mathrm{v}} 3.1, \mathrm{Ca}_{\mathrm{v}} 3.2$, and $\mathrm{Ca}_{\mathrm{v}} 3.3$ from $\mathrm{MHb}$ slices because of non-normally distributed data (Shapiro-Wilk $p<0.05$ ), followed by Dunn's post hoc multiple comparison testing. $\mathrm{Ca}_{\mathrm{v}} 3.1$ expression in the medial versus lateral $\mathrm{MHb}$ was analyzed by unpaired $t$ test. The voltage-dependencies of activation and inactivation were described by the following Boltzmann functions:

$$
\begin{gathered}
\text { Activation : } G(V)=G_{\max } /\left(1+\exp \left[-\left(V-V_{50}\right) / \mathrm{k}\right]\right) \\
\text { Inactivation }: I(V)=I_{\max } /\left(1+\exp \left[\left(V-V_{50}\right) / k\right]\right)
\end{gathered}
$$

\section{Results}

\section{Diverse electrophysiological states of $\mathrm{MHb}$ neurons}

Cell-attached and whole-cell patch-clamp recordings were made to determine the activity state of $\mathrm{MHb}$ neurons at baseline. In whole-cell recordings, an assessment was made in the first few seconds to avoid alteration of cell state by the internal solution. MHb neurons exhibited a variety of distinct activity states at baseline. About half (66 of $130,50.8 \%$ ) of $\mathrm{MHb}$ neurons exhibited spontaneous, tonic AP firing at a frequency of $\sim 2-10 \mathrm{~Hz}$ (Fig. 1A,F). About a third (43 of $130,33.1 \%)$ were electrophysiologically silent (Fig. 1B,F). A minority (12 of $130,9.2 \%)$ of $\mathrm{MHb}$ 


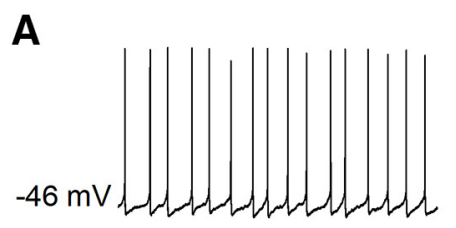

B
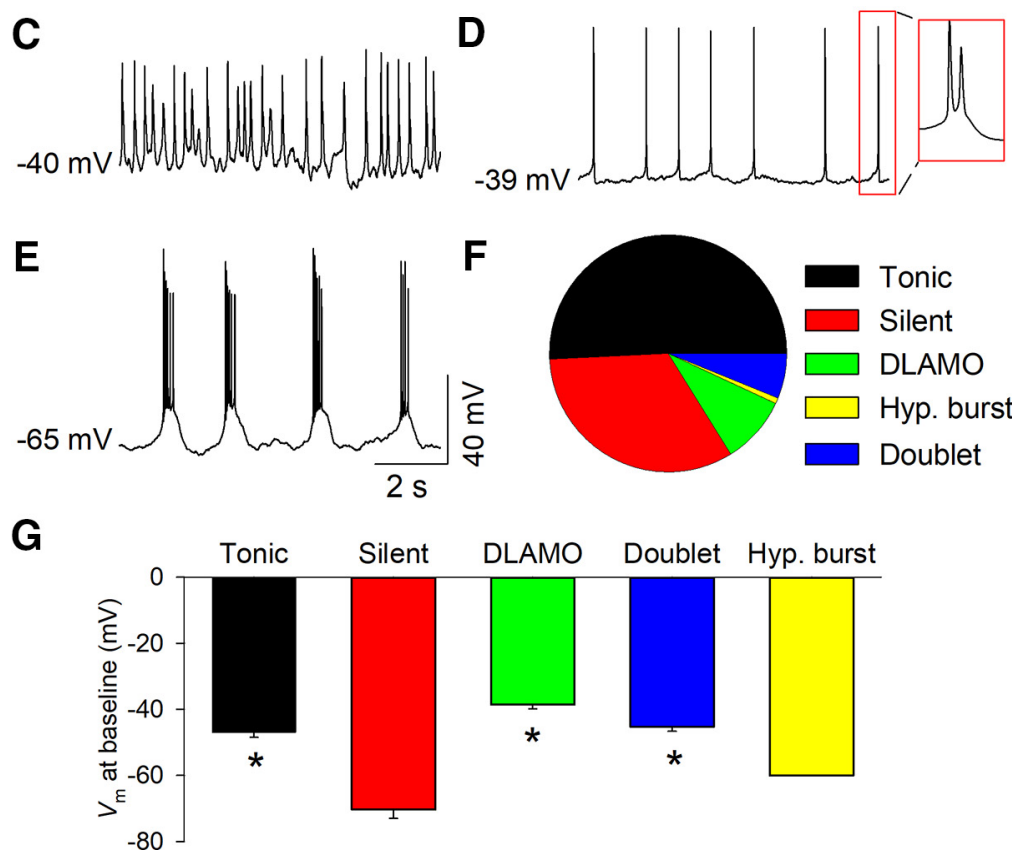

Figure 1. Diverse activity states of $\mathrm{MHb}$ neurons. MHb neurons displayed diverse activity states at baseline. The majority of neurons exhibited tonic AP firing $(\boldsymbol{A})$, whereas others were silent $(\boldsymbol{B})$, displayed DLAMOs $(\boldsymbol{C})$, fired AP doublets at depolarized membrane potentials $(\boldsymbol{D})$, or bursted at a hyperpolarized membrane potential $(\boldsymbol{E})$. $\boldsymbol{F}$, Percent of MHb neurons that displayed different activity states at baseline. G, Average resting membrane potential of different cell states; $* p<0.05$ versus silent. Hyp., hyperpolarized.

neurons exhibited depolarized low-amplitude membrane oscillations (DLAMOs; Fig. 1C,F), characterized by oscillatory fluctuations in membrane potential $\left(V_{\mathrm{m}}\right.$; Sakhi et al., 2014). Additionally, we observed a small population of neurons that exhibited high-frequency AP firing. At baseline, most spontaneously high-frequency $\mathrm{AP}$ firing $\mathrm{MHb}$ neurons fired AP doublets at a frequency of $\sim 75-125 \mathrm{~Hz}$ at an average resting $V_{\mathrm{m}}$ of $-45.2 \pm 1.5 \mathrm{mV}$ (Fig. $1 D ; 8$ of 130 total neurons, 6.2\%; Fig. $1 F$ ), whereas one neuron spontaneously fired long trains of APs on top of a prominent depolarized plateau potential followed by an afterdepolarization (Fig. 1E; 1 of 130 total neurons, 0.8\%; Fig. $1 F$ ). The average intraburst frequency was $27.2 \pm 1.8 \mathrm{~Hz}$, and the average interburst interval was $2.3 \pm 0.6 \mathrm{~s}$ in this neuron. The average resting $V_{\mathrm{m}}$ in silent cells was significantly more hyperpolarized relative to that in tonic, silent, DLAMO, and depolarized doublet firing $\mathrm{MHb}$ neurons (Fig. 1G). Thus, MHb neurons display a variety of electrophysiological states at baseline, including high-frequency AP firing that has not been previously reported.

\section{Burst firing from hyperpolarized membrane potentials}

Although burst firing in $\mathrm{MHb}$ neurons has not been previously reported, neurons of the nearby LHb and thalamus display burst firing that resembles the hyperpolarized burst firing we observed, which is mediated by the activation of T-type $\mathrm{Ca}^{2+}$ channels (Wilcox et al., 1988; PerezReyes, 2003; Chang and Kim, 2004; Cheong and Shin, 2013; Lambert et al., 2014; Cui et al., 2018; Yang et al., 2018). T-type channels are a member of the low-voltage activated (LVA) family of voltage-gated $\mathrm{Ca}^{2+}$ channels (Perez-Reyes, 2003; Cheong and Shin, 2013). They can be activated by low-level membrane depolarization, though sustained depolarization leads to channel inactivation and can cause a switch to tonic firing (McCormick and Pape, 1990). We thus tested whether depolarization of $\mathrm{MHb}$ neurons from a hyperpolarized $V_{\mathrm{m}}$ can trigger burst firing and whether prolonged depolarization causes a transition to tonic firing.

In a silent $\mathrm{MHb}$ neuron, a depolarization step (10 pA) from the resting $V_{\mathrm{m}}(-63 \mathrm{mV})$ triggered high-frequency AP firing (AP frequency $=85 \mathrm{~Hz}$ ) that resembled the hyperpolarized burst firing observed in Figure $1 E$, in that it fired a train of APs on top of a depolarized plateau potential and was followed by a large afterdepolarization (Fig. 2A). When the $V_{\mathrm{m}}$ was changed to $-58 \mathrm{mV}$ through constant current injection $(10 \mathrm{pA})$, the same depolarization step (10 pA) triggered transient burst firing at $34 \mathrm{~Hz}$, followed by tonic firing at $3.5 \mathrm{~Hz}$. When the $V_{\mathrm{m}}$ was further depolarized to $-52 \mathrm{mV}$ by $20-\mathrm{pA}$ constant current injection, the 10-pA depolarization step triggered tonic firing at $3.8 \mathrm{~Hz}$. 
A
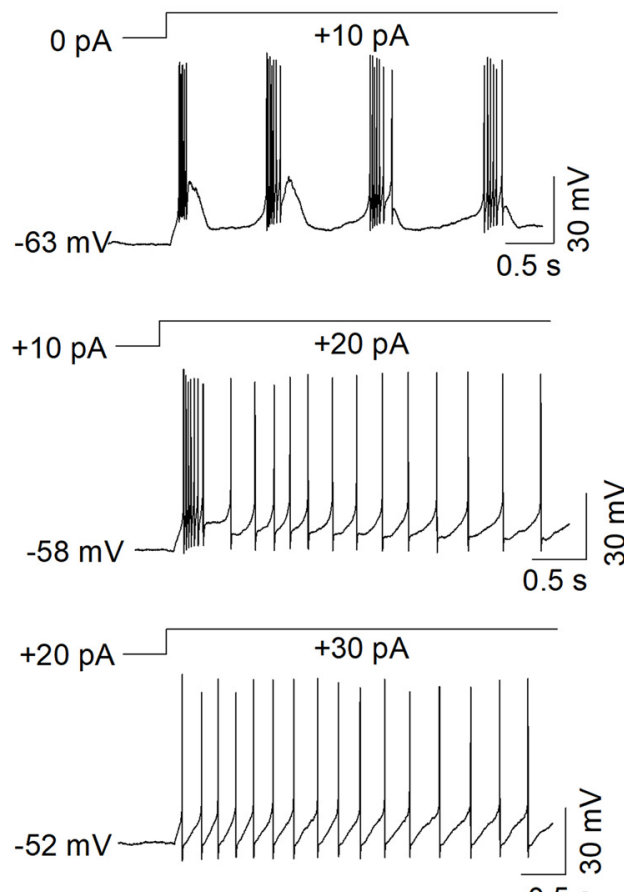

B

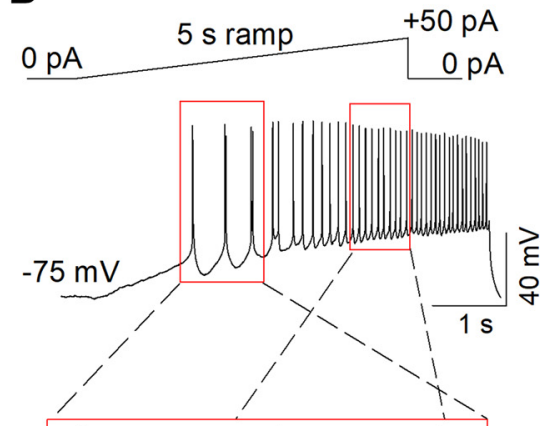

C
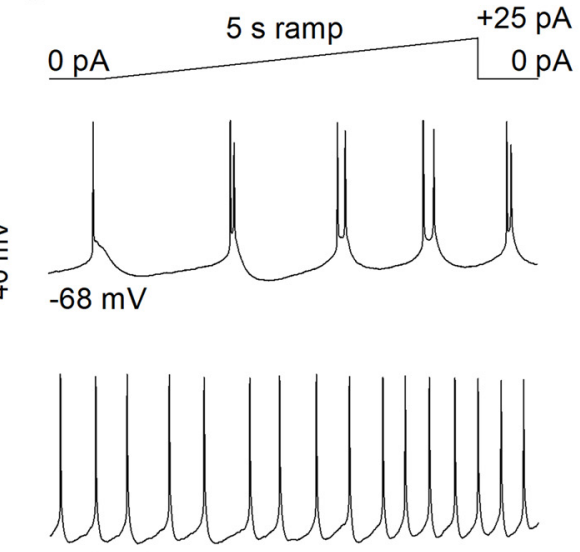

$-57 \mathrm{mV}$

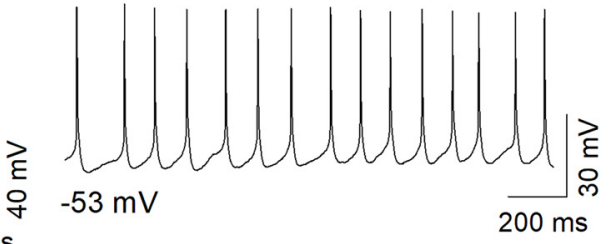

Figure 2. Depolarization from hyperpolarized membrane potentials triggered burst firing in a subset of MHb neurons. $\boldsymbol{A}$, Step depolarization triggered burst firing from a resting $V_{\mathrm{m}}$ of $-63 \mathrm{mV}$. With constant current injection to a $V_{\mathrm{m}}$ of $-58 \mathrm{mV}$, step depolarization triggered initial burst firing followed by tonic firing. With constant current injection to a $V_{\mathrm{m}}$ of $-52 \mathrm{mV}$, step depolarization triggered solely tonic firing. $\boldsymbol{B}$, Ramp depolarization from a $V_{\mathrm{m}}<-60 \mathrm{mV}$ triggered initial burst firing in 30 of $152 \mathrm{MHb}$ neurons (19.7\%). Tonic firing was observed as the $V_{\mathrm{m}}$ depolarized above approximately $-55 \mathrm{mV}$. C. Bursting was observed when the $V_{\mathrm{m}}$ was $-68 \mathrm{mV}$ before ramp depolarization but was abolished with constant current injection to -57 or $-53 \mathrm{mV}$ before the ramp.

Similarly, ramp depolarization (0 to $+50 \mathrm{pA}$ ramp, 5-s duration) from a resting $V_{\mathrm{m}}$ of $-75 \mathrm{mV}$ triggered initial burst firing in an $\mathrm{MHb}$ neuron (Fig. 2B). As the $V_{\mathrm{m}}$ became more depolarized during the ramp, burst firing transitioned to tonic firing. Burst firing remained when the $V_{\mathrm{m}}$ was more hyperpolarized than approximately $-55 \mathrm{mV}$ but transitioned to tonic firing as the $V_{\mathrm{m}}$ depolarized above this level. At a $V_{\mathrm{m}}$ of $-44 \mathrm{mV}$, only repetitive tonic firing was observed. In a different $\mathrm{MHb}$ neuron, initial burst firing to ramp depolarization was similarly observed from a resting $V_{\mathrm{m}}$ of $-68 \mathrm{mV}$, but burst firing was not observed with constant current injection to -57 or $-53 \mathrm{mV}$ before the ramp (Fig. 2C). Ramp depolarization-induced burst firing from a hyperpolarized $V_{\mathrm{m}}(<-60 \mathrm{mV}$ before ramp) triggered initial burst firing in 30 of $152 \mathrm{MHb}$ neurons (19.7\%). Burst firing from a hyperpolarized $V_{\mathrm{m}}$ that is abolished by holding the neuron at depolarized potentials suggests that T-type channel activation contributes to the initial burst firing.

T-type channels are nearly completely inactivated when neurons are held at a $V_{\mathrm{m}}>-60 \mathrm{mV}$ (Perez-Reyes, 2003; Cheong and Shin, 2013). As the average $V_{m}$ of tonic neurons was $-47.0 \pm 1.5 \mathrm{mV}$, it is possible that membrane hyperpolarization may convert these neurons to burst firing neurons. In a tonic firing cell with a resting $V_{\mathrm{m}}$ of $-40 \mathrm{mV}$, ramp hyperpolarization ( 0 to $-20 \mathrm{pA}, 5 \mathrm{~s}$ ) converted tonic firing to burst firing (Fig. $3 A$ ). Tonic firing resumed after the $V_{\mathrm{m}}$ spontaneously depolarized above $-50 \mathrm{mV}$. Thus, $\mathrm{MHb}$ neuron firing states can be interchangeable depending on their $V_{\mathrm{m}}$.
We evaluated whether the offset of a prolonged hyperpolarizing current step could induce rebound burst firing. A series of hyperpolarizing current steps (0 to $-50 \mathrm{pA}$, $\Delta 50 \mathrm{~ms}$ ) triggered rebound burst firing in an $\mathrm{MHb}$ neuron (Fig. 3B). Interestingly, as the hyperpolarization duration lengthened, the high-frequency rebound burst was converted to a single AP with a pronounced afterdepolarization, subsequently followed by a spontaneous, high-frequency AP burst. Similarly, progressively greater hyperpolarizing current steps $(0$ to $-80 \mathrm{pA}, \Delta 20 \mathrm{pA}$, $100 \mathrm{~ms}$ ) triggered rebound burst firing (Fig. 3C). Rebound burst firing following the offset of a prolonged hyperpolarizing current step $(\geq 1 \mathrm{~s},-50 \mathrm{pA}$ ) was observed in $19.3 \%$ (29 of 150) neurons recorded (Fig. 3D). Burst firing from a hyperpolarized $V_{\mathrm{m}}$ could be observed in $\mathrm{MHb}$ neurons from all baseline activity states but was most commonly observed in tonic firing neurons (Fig. 3E). Thus, depolarization from a hyperpolarized $V_{\mathrm{m}}$, or hyperpolarization alone, can trigger burst firing in $\sim 20 \%$ of $\mathrm{MHb}$ neurons.

\section{T-type channel expression in the $\mathrm{MHb}$}

T-type channels are encoded by three genes: CACNA1G, CACNA1H, and CACNA1I, which encode the pore-forming $\alpha 1$ subunits $\mathrm{Ca}_{\mathrm{v}} 3.1, \mathrm{Ca}_{\mathrm{v}} 3.2$, and $\mathrm{Ca}_{\mathrm{v}} 3.3$ (Perez-Reyes, 2003). We used RNAscope fluorescent in situ hybridization (Wang et al., 2012) to determine whether mRNA for T-type channels is expressed in the $\mathrm{MHb}$ and to determine the cell populations that express these 
A

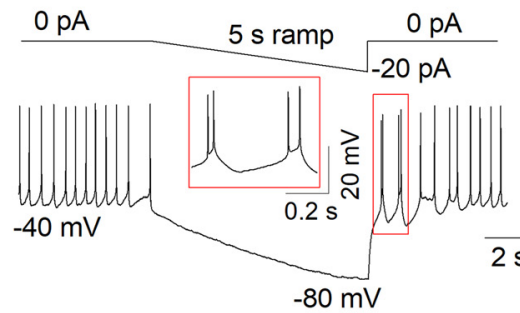

B

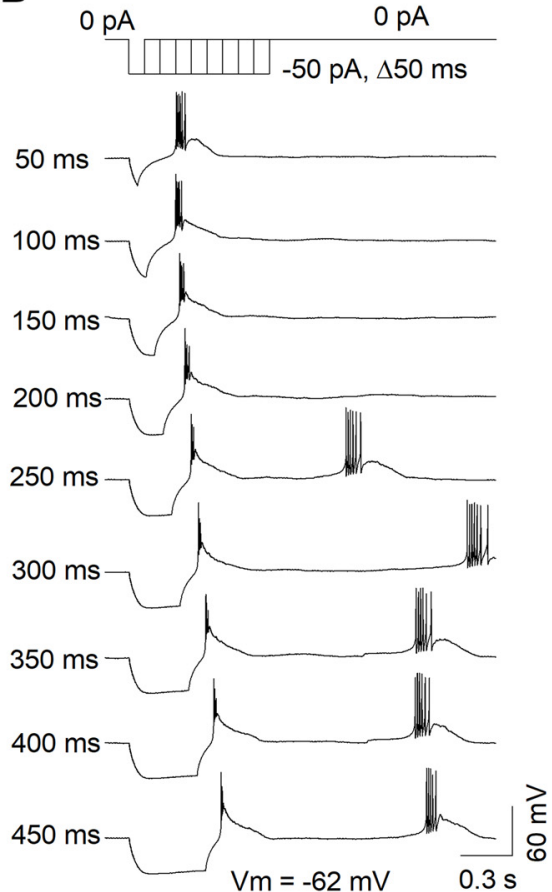

C

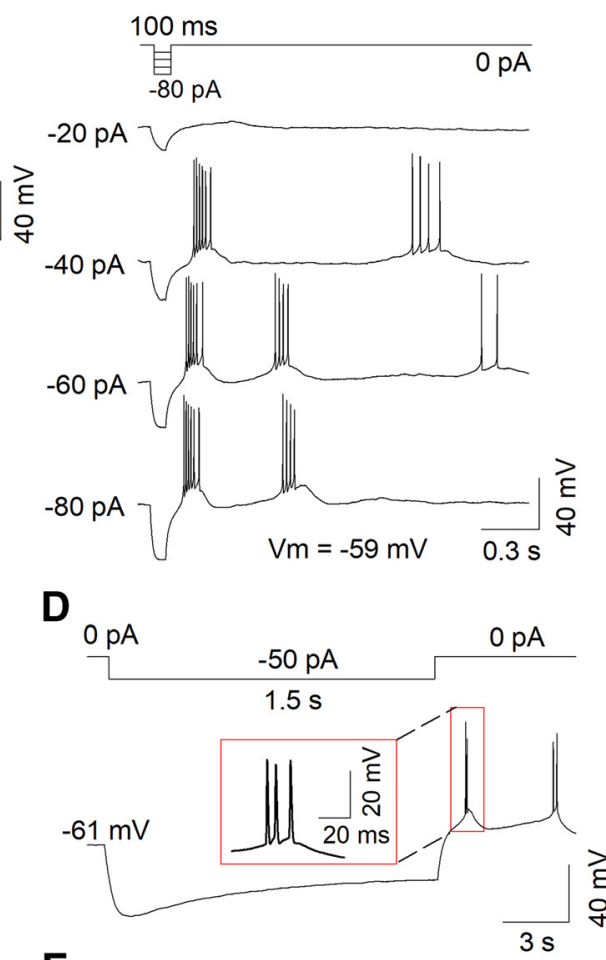

E

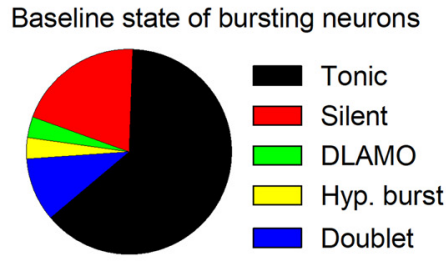

Figure 3. Hyperpolarization triggered burst firing in a subset of MHb neurons. $\boldsymbol{A}$, Ramp hyperpolarization in a tonic firing neuron with a resting $V_{\mathrm{m}}$ of $-40 \mathrm{mV}$ converted tonic firing to burst firing. $\boldsymbol{B}$, Progressively longer hyperpolarizing current injections triggered rebound burst firing in an $\mathrm{MHb}$ neuron. $\mathbf{C}$, Progressively greater hyperpolarizing current injections triggered rebound burst firing in an $\mathrm{MHb}$ neuron. $\boldsymbol{D}, \mathrm{A} 1.5$-s-long hyperpolarizing current injection triggered rebound burst firing in an $\mathrm{MHb}$ neuron. $\boldsymbol{E}$, Baseline state of $\mathrm{MHb}$ neurons that displayed burst firing from a hyperpolarized $V_{\mathrm{m}}(<-60 \mathrm{mV})$.

channels. We found that mRNA for $\mathrm{Ca}_{\mathrm{v}} 3.1$ was abundantly expressed in the $\mathrm{MHb}$, including in both Tac1+ and ChAT+ neurons (Fig. 4). Expression of $\mathrm{Ca}_{\mathrm{v}} 3.2$ and $\mathrm{Ca}_{\mathrm{v}} 3.3$ was also observed in the MHb in both Tac1+ and ChAT+ neurons, albeit at significantly lower levels than $\mathrm{Ca}_{\mathrm{v}} 3.1$ (Fig. 5A,B). Ca 3.1 expression was significantly greater in the lateral $\mathrm{MHb}$ relative to the medial $\mathrm{MHb}$ (Fig. $5 C)$. Thus, mRNA for T-type channels, in particular $\mathrm{Ca}_{\mathrm{v}} 3.1$, are expressed in the $\mathrm{MHb}$ in both major neuron populations.

\section{Dependence of bursting on T-type channels}

We recorded the locations of $\mathrm{MHb}$ neurons that displayed high-frequency AP firing from a hyperpolarized $V_{\mathrm{m}}$. Of the 35 neurons where location information was recorded, 27 of $35(77.1 \%)$ of these neurons were in the lateral or central $\mathrm{MHb}$ (Fig. 6), consistent with the highest $\mathrm{Ca}_{\mathrm{v}} 3$ expression in this area. We therefore tested whether pharmacological blockade of T-type channels affected burst firing in $\mathrm{MHb}$ neurons in this region. $\mathrm{MHb}$ neurons that exhibited ramp depolarization-induced burst firing from a $V_{m}<-60 \mathrm{mV}$ were bath-perfused with the selective T-type channel antagonist Z944 (3 $\mu \mathrm{M})$. Z944 significantly reduced the number of bursts per ramp (before Z944: $2.7 \pm 0.4$, after Z944: $0.2 \pm 0.1 ; t_{(5)}=6.2, p=0.002$, $n=6$; Fig. 7). Further, Z944 abolished burst firing in a neuron that bursted with ramp depolarization from a $V_{\mathrm{m}}$ of $-75 \mathrm{mV}$ but not from a $V_{\mathrm{m}}$ of $-54 \mathrm{mV}$ (data not shown). $\mathrm{MHb}$ neurons that exhibited rebound bursting were bathperfused with Z944 (Fig. 8). With 1.5-s hyperpolarizing current pulses, Z944 significantly reduced the number of rebound bursts (before Z944: 1.4 \pm 0.4 , after Z944: $\left.0.1 \pm 0.1 ; t_{(5)}=2.9, p=0.035, n=6\right)$ and rebound AP frequency (before Z944: $87.6 \pm 21.8 \mathrm{~Hz}$, after Z944: $13.2 \pm$ $3.8 \mathrm{~Hz} ; t_{(6)}=3.7, p=0.010, n=7$; Fig. $\left.8 A-C\right)$. With 100-ms hyperpolarizing current pulses, Z944 significantly reduced the number of rebound bursts (before Z944: $1.2 \pm 0.2$, after Z944: $0.0 \pm 0.0 ; t_{(4)}=6.0, p=0.004, n=5$ ) and rebound AP frequency (before Z944: $49.2 \pm 15.5 \mathrm{~Hz}$, after 

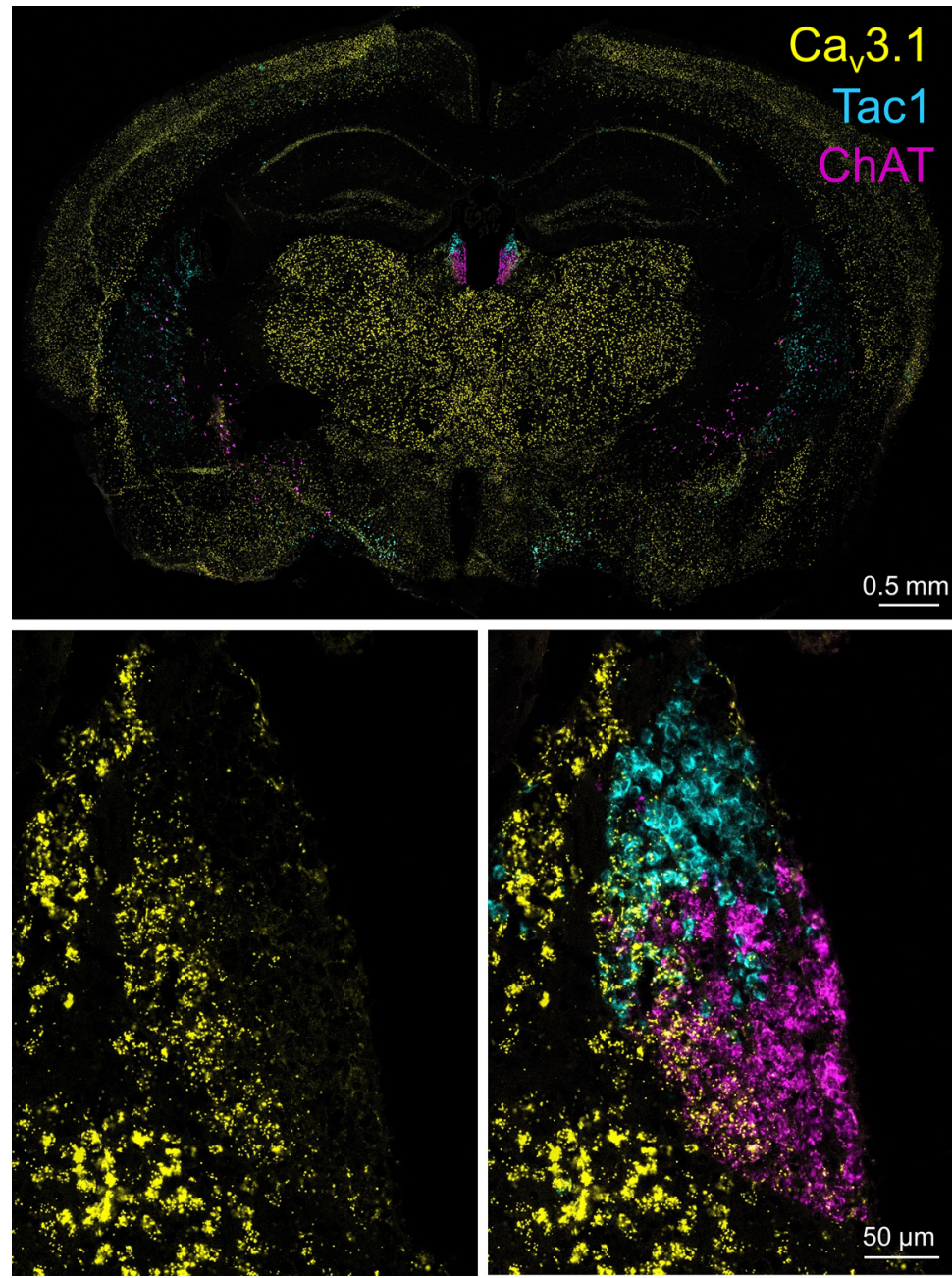

Figure 4. $\mathrm{Ca}_{\mathrm{v}} 3.1$ is expressed in the $\mathrm{MHb}$. RNAscope in situ hybridization demonstrated that mRNA for $\mathrm{Ca}_{\mathrm{v}} 3.1$ is expressed in the $\mathrm{MHb}$, in particular its lateral aspect. Both Tac1+ and ChAT+ neurons express $\mathrm{Ca}_{\mathrm{v}} 3.1 \mathrm{mRNA}$.

Z944: $5.6 \pm 3.6 \mathrm{~Hz} ; t_{(5)}=3.0, p=0.029, n=6$; Fig. $8 D-F$ ). Thus, T-type channel activation contributes to both depolarization-induced burst firing from a hyperpolarized $V_{m}$ and rebound burst firing.

A previous study found that NMDA and AMPA receptor activation contributes to burst firing in the LHb (Yang et al., 2018). In MHb neurons which exhibited ramp depolarization-induced burst firing from a $V_{\mathrm{m}}<-60 \mathrm{mV}$, the NMDA receptor antagonists CPP $(5 \mu \mathrm{M})$ or AP-5 $(50 \mu \mathrm{M})$ were bath-perfused. Neither CPP nor AP-5 significantly affected the number of bursts per ramp (before CPP: $6.0 \pm 1.2$, after CPP: $6.8 \pm 1.1 ; t_{(3)}=-1.42, p=0.25, n=4$; before AP-5: $3.2 \pm 0.7$, after AP-5: $2.4 \pm 0.4 ; t_{(4)}=1.4$, $p=0.24, n=5$ ) or the average number of APs per burst (before CPP: $2.3 \pm 0.2$, after CPP: $2.2 \pm 0.1 ; t_{(3)}=0.65$, $p=0.57, n=4$; before AP-5: $2.1 \pm 0.1$, after AP-5: $2.4 \pm$ $\left.0.2 ; t_{(4)}=-2.3, p=0.08, n=5\right)$. Similarly, the AMPA receptor antagonist CNQX did not significantly affect the number of bursts per ramp (before CNQX: $3.2 \pm 0.7$, after CNQX: $2.6 \pm 0.5 ; t_{(4)}=2.5, p=0.07, n=5$ ) or the average number of APs per burst (before CNQX: $2.1 \pm 0.1$, after CNQX: $\left.2.1 \pm 0.1 ; t_{(4)}=0.02, p=0.99, n=5\right)$. Therefore, tonic synaptic glutamate does not contribute to depolarization-induced burst firing from a hyperpolarized $V_{\mathrm{m}}$ in $\mathrm{MHb}$ neurons in brain slices.

\section{Voltage-gated $\mathrm{Ca}^{2+}$ currents in $\mathrm{MHb}$ neurons}

Next, we tested whether voltage-gated $\mathrm{Ca}^{2+}$ currents could be evoked in $\mathrm{MHb}$ neurons, and we determined the voltage dependence of their activation and inactivation. $\mathrm{Ca}^{2+}$ currents were recorded similarly to previous studies (Joksimovic et al., 2017; Stamenic and Todorovic, 2018), using an internal solution that caused rapid rundown of high-voltage activated (HVA) $\mathrm{Ca}^{2+}$ currents (Todorovic and Lingle, 1998). $\mathrm{Ca}^{2+}$ current activation was studied using a step depolarization protocol where $\mathrm{MHb}$ neurons were stepped to progressively more depolarized holding potentials for $320 \mathrm{~ms}$ after initially holding neurons at $-90 \mathrm{mV}$ for $1 \mathrm{~s}$ (Fig. 9A). Rapid inward currents were evoked, and the conductance versus voltage relationship was fit with a Boltzmann function. The average voltage of half-activation $\left(V_{50}\right)$ in the absence of Z944 was $-47.9 \mathrm{mV}$. There was a significant effect of Z944 to 

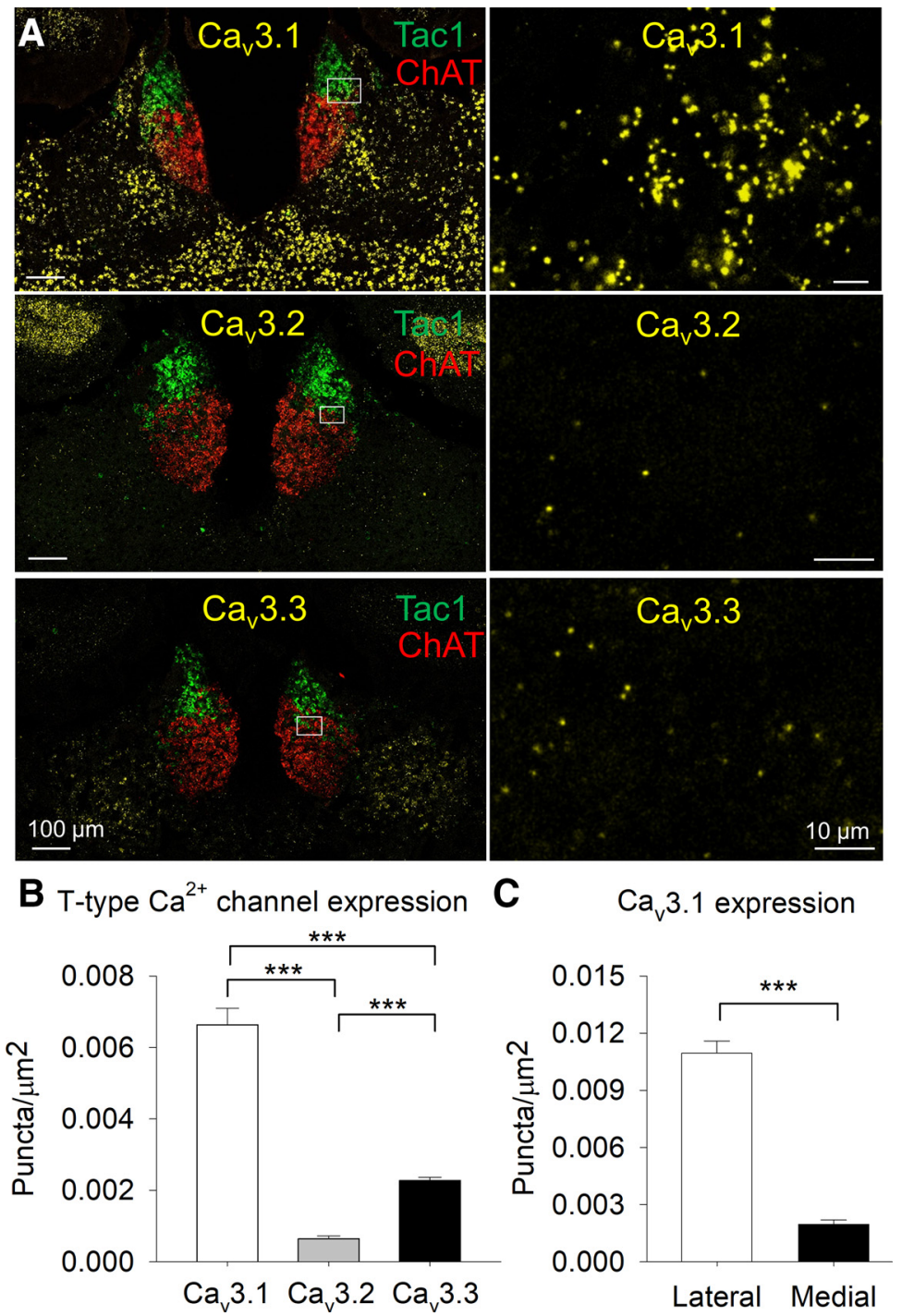

Figure 5. T-type channel expression in the MHb. $\boldsymbol{A}$, RNAscope in situ hybridization for $\mathrm{Ca}_{\mathrm{v}} 3.1, \mathrm{Ca}_{\mathrm{v}} 3.2$, and $\mathrm{Ca}_{\mathrm{v}} 3.3 \mathrm{mRNA}$ in the $\mathrm{MHb}$ with Tac1 and ChAT. $\boldsymbol{B}$, Expression of $\mathrm{Ca}_{\mathrm{v}} 3.1$ is significantly greater than $\mathrm{Ca}_{\mathrm{v}} 3.2$ and $\mathrm{Ca}_{\mathrm{v}} 3.3$ expression, and $\mathrm{Ca}_{\mathrm{v}} 3.3$ expression is significantly greater than $\mathrm{Ca}_{\mathrm{v}} 3.2$ in the $\mathrm{MHb} ; * * *<0.001$. $\mathbf{C}, \mathrm{Ca}_{\mathrm{v}} 3.1$ expression is significantly greater in the lateral $\mathrm{MHb}$ than the medial $\mathrm{MHb} ; * * * p<0.001$.

reduce $\mathrm{Ca}^{2+}$ current amplitude (two-way ANOVA with repeated measures: $F_{(1,79)}=246.4, p<0.001$; Holm-Sidak post hoc test: $p<0.001$ ). Thus, $\mathrm{Ca}^{2+}$ currents can be evoked in $\mathrm{MHb}$ neurons and are sensitive to T-type channel blockade.

The voltage dependence of $\mathrm{Ca}^{2+}$ current inactivation was determined by holding $\mathrm{MHb}$ neurons for $3.6 \mathrm{~s}$ at progressively more depolarized membrane potentials before a 320 -ms step to $-50 \mathrm{mV}$ (Fig. 9B). Rapid inward currents were evoked when neurons were pre-held at hyperpolarized membrane potentials but were not evoked when preheld at more depolarized potentials. A plot of the current versus initial holding voltage was fit with a Boltzmann function. The average voltage of half-inactivation $\left(V_{50}\right)$ was $-92.6 \mathrm{mV}$. These voltages of half-activation and halfinactivation are consistent with those measured for Ttype channels in the rat subiculum using an identical internal solution and voltage protocols (Joksimovic et al., 2017). Collectively, these results indicate that evoked $\mathrm{Ca}^{2+}$ currents in $\mathrm{MHb}$ neurons are likely to be mediated by T-type channels.

\section{Depolarized AP doublets}

Eight of 130 total neurons $(6.2 \%)$ spontaneously fired AP doublets and had an average $V_{m}$ of $-43.9 \pm 1.5 \mathrm{mV}$ (Fig. $1 D$ ). As T-type channels are likely completely inactivated at this $V_{m}$, we aimed to further characterize the electrophysiological characteristics of depolarized AP doublet firing. In a depolarized $\left(V_{\mathrm{m}}=-44 \mathrm{mV}\right)$ neuron displaying both spontaneous AP doublets and single spikes with a large afterdepolarization, low-level ramp depolarization (5 pA, $5 \mathrm{~s})$ increased AP doublet firing at a $V_{\mathrm{m}}$ of $-39 \mathrm{mV}$ (Fig. 10A). In a different $\mathrm{MHb}$ neuron that spontaneously fired AP doublets at a $V_{\mathrm{m}}$ of 


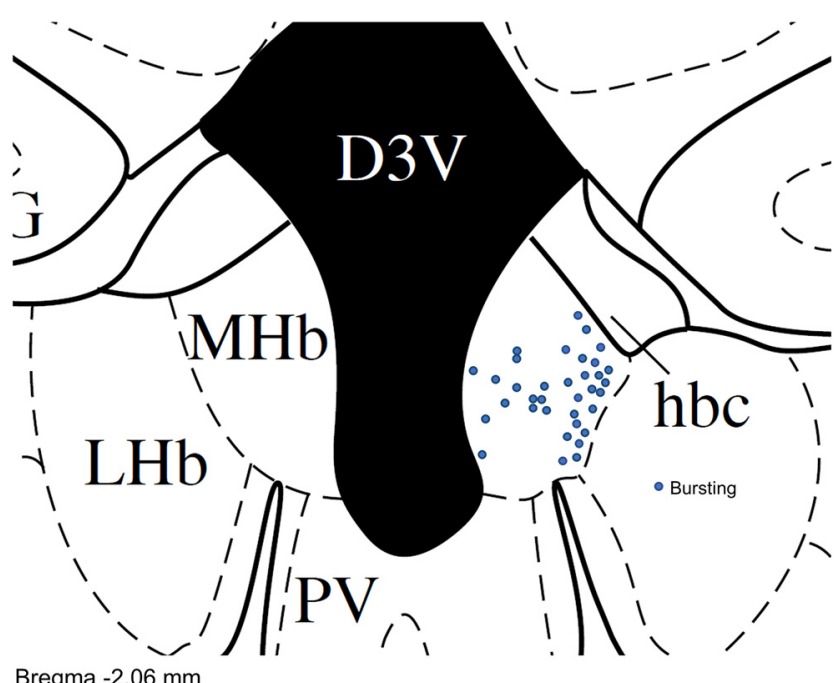

Bregma $-2.06 \mathrm{~mm}$

Figure 6. Location of neurons that bursted from a hyperpolarized membrane potential. Neurons that bursted from a $V_{\mathrm{m}}$ $<-60 \mathrm{mV}$ were predominantly located in the lateral and central $\mathrm{MHb}$. Map includes neurons that bursted to ramp depolarization and/or to step hyperpolarization.

$-48 \mathrm{mV}$, membrane hyperpolarization ( $-50 \mathrm{pA}, 300 \mathrm{~ms})$ briefly converted depolarized AP doublet firing to tonic firing at a $V_{\mathrm{m}}$ of $-53 \mathrm{mV}$, followed by a return to AP doublet firing with spontaneous depolarization to a $V_{m}$ of $-48 \mathrm{mV}$ (Fig. $10 B$ ). Spontaneous AP doublets at depolarized membrane potentials were not blocked by perfusion with Z944 (Fig. $10 C ; n=5)$. Thus, AP doublet firing at sustained depolarized potentials does not require T-type channel activation.

\section{Discussion}

In this study, we found that a subpopulation of $\mathrm{MHb}$ neurons are capable of firing high-frequency AP bursts from a hyperpolarized $V_{m}$ that strongly resemble burst firing mediated by T-type $\mathrm{Ca}^{2+}$ channel activation (Llinás and Jahnsen, 1982; McCormick and Pape, 1990; Cheong and Shin, 2013; Lambert et al., 2014). This burst firing could be induced by rebounding from membrane hyperpolarization or depolarization from a hyperpolarized $V_{\mathrm{m}}$, whereas depolarization from a $V_{\mathrm{m}}>-60 \mathrm{mV}$ led to tonic AP firing or depolarized AP doublet firing. Using RNAscope in situ hybridization, we identified robust mRNA expression of the Ttype $\mathrm{Ca}^{2+}$ channel $\mathrm{Ca}_{v} 3.1$ primarily in the lateral $\mathrm{MHb}$, where it co-localized with both ChAT and Tac1, markers which define the ventral and dorsal $\mathrm{MHb}$, respectively (Molas et al., 2017). Expression of $\mathrm{Ca}_{\mathrm{v}} 3.2$ and $\mathrm{Ca}_{\mathrm{v}} 3.3$ was also observed in the MHb but was comparatively sparse. Hyperpolarization-induced and depolarization-induced burst firing from a hyperpolarized $V_{\mathrm{m}}$, and evoked $\mathrm{Ca}^{2+}$ currents, were blocked by bath perfusion of the selective $\mathrm{Ca}_{\mathrm{v}} 3$ antagonist Z944. Thus, a subpopulation of $\mathrm{MHb}$ neurons are capable of high-frequency burst firing, in contrast to previous reports of exclusive tonic firing by $\mathrm{MHb}$ neurons, with burst firing from a hyperpolarized $V_{\mathrm{m}}$ sensitive to T-type channel blockade.

Interestingly, single-cell RNA sequencing of the mouse habenula revealed that transcriptomically defined clusters of $\mathrm{MHb}$ neurons heterogeneously express $\mathrm{Ca}_{\mathrm{v}} 3.1$ (Hashikawa et al., 2019). The highest $\mathrm{Ca}_{\mathrm{v}} 3.1$ expression was observed in neuron clusters located in the lateral aspect of both the dorsal and ventral $\mathrm{MHb}$ and in clusters which express Tac1 or ChAT, consistent with our results. This study also identified mRNA for $\mathrm{Ca}_{\mathrm{v}} 3.3$ in some $\mathrm{MHb}$ clusters. A previous autoradiographic ISH study concluded that mRNA for $\mathrm{Ca}_{\mathrm{v}} 3.1$ was expressed in the LHb but not the MHb (Talley et al., 1999), and hyperpolarization-induced rebound burst firing mediated by T-type channels has been observed in the LHb (Cui et al., 2018; Yang et al., 2018).

Voltage-gated $\mathrm{Ca}^{2+}$ channels fall into two broad categories: HVA and LVA channels (Perez-Reyes, 2003; Cheong and Shin, 2013). T-type $\mathrm{Ca}^{2+}$ channels are LVA channels, whereas the other families of voltage-gated $\mathrm{Ca}^{2+}$ channels, including L-type, P/Q-type, N-type, and R-type channels, are HVA channels. Unique properties of T-type $\mathrm{Ca}^{2+}$ channels differentiate them from the HVA family. In contrast to HVA channels, T-type $\mathrm{Ca}^{2+}$ channels
A

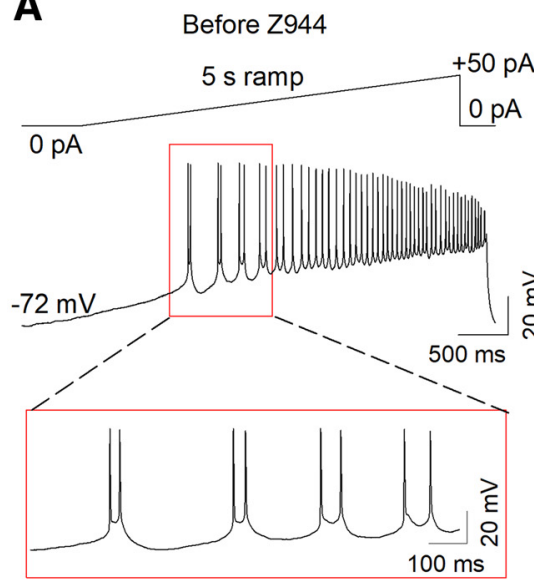

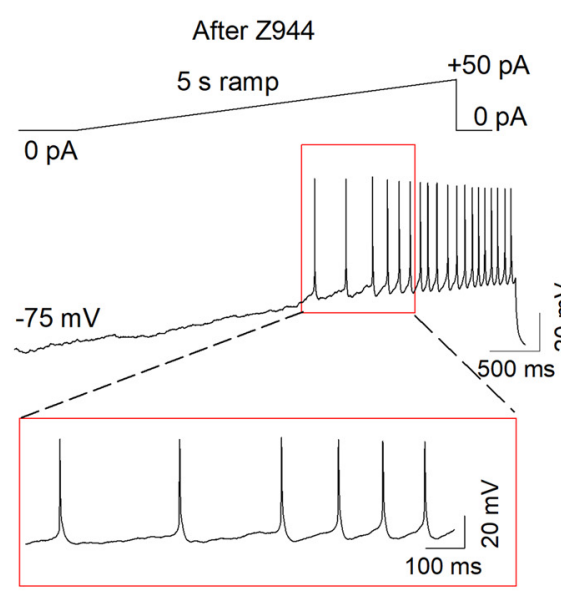

B

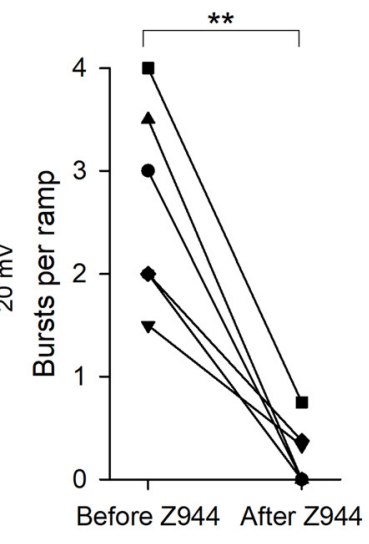

Figure 7. The selective T-type channel antagonist Z944 blocked ramp depolarization-induced burst firing from hyperpolarized membrane potentials. $\boldsymbol{A}$, Representative traces demonstrating the effect of Z944 to block ramp-induced burst firing from a hyperpolarized $V_{\mathrm{m}}$. B , The number of bursts per ramp was significantly reduced following Z944 perfusion; $* * p<0.01$. 

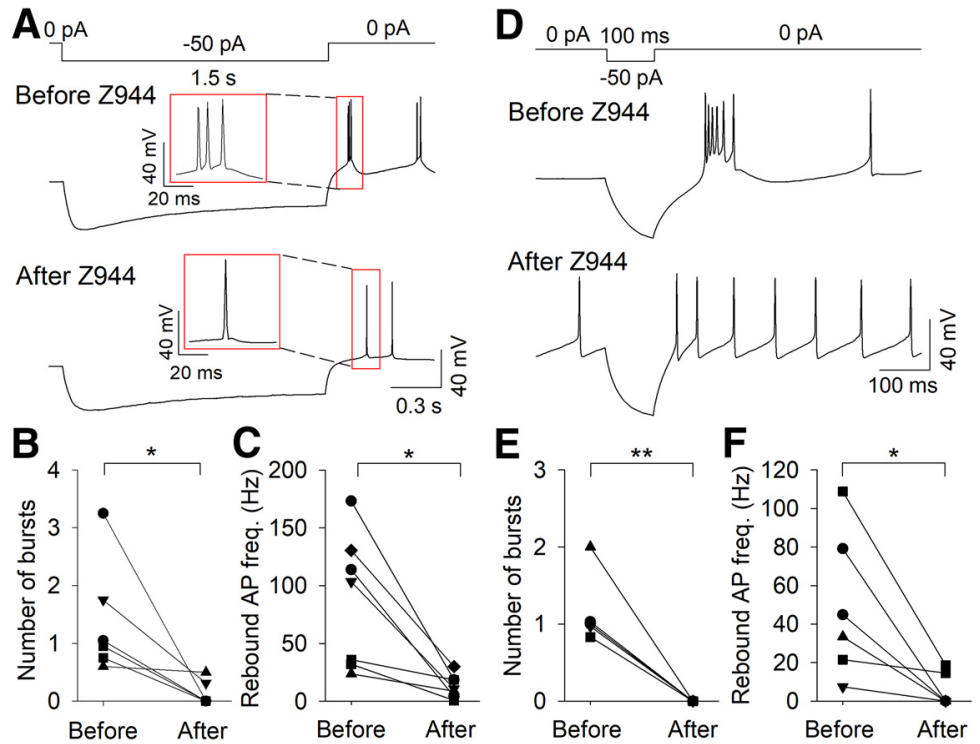

Figure 8. The selective T-type channel antagonist Z944 blocked rebound burst firing. Representative traces demonstrating the effect of Z944 to block rebound burst firing following 1.5-s (A) or 100-ms $(\boldsymbol{D})$ hyperpolarization. The number of bursts and rebound AP frequency were significantly reduced following 1.5-s $(\boldsymbol{B}, \boldsymbol{C})$ or $100-\mathrm{ms}(\boldsymbol{E}, \boldsymbol{F})$ hyperpolarization after Z944 perfusion; $* p<0.05$, $* * p<0.01$.

require less membrane depolarization to open and rapidly inactivate with prolonged depolarization, leading to lowthreshold $\mathrm{Ca}^{2+}$ spikes (LTS) that can trigger a burst of $\mathrm{Na}^{+}$and $\mathrm{K}^{+}$-mediated APs on top of the $\mathrm{Ca}^{2+}$-mediated LTS. In neurons with a resting membrane potential of $-60 \mathrm{mV}$, the majority of T-type $\mathrm{Ca}^{2+}$ channels are inactivated, such that membrane hyperpolarization alleviates inactivation and leads to rebound burst firing on subsequent depolarization (Perez-Reyes, 2003; Cheong and Shin, 2013). In more hyperpolarized neurons, depolarization can trigger burst firing, but sustained and/or stronger depolarization inactivates T-type $\mathrm{Ca}^{2+}$ channels and prevents burst firing (Perez-Reyes, 2003; Cheong and Shin, 2013).

We observed that $\sim 20 \%$ of $\mathrm{MHb}$ neurons burst fired to ramp depolarization from a hyperpolarized $V_{\mathrm{m}}$ or
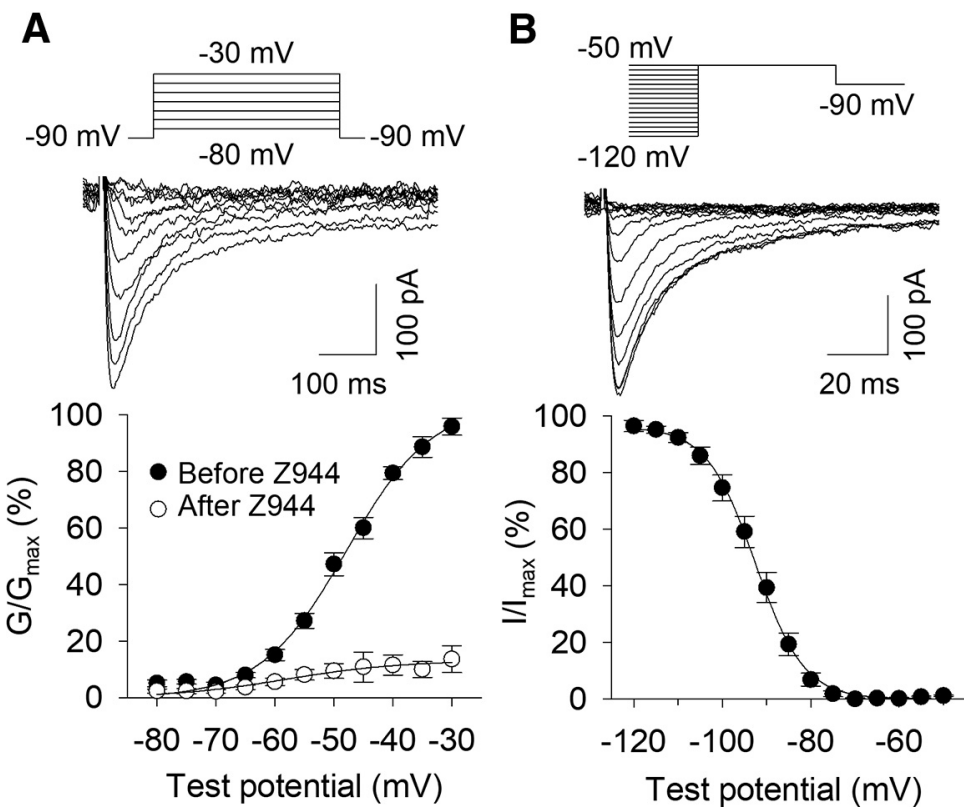

Figure 9. Voltage-gated $\mathrm{Ca}^{2+}$ currents in $\mathrm{MHb}$ neurons. A, top, Representative currents induced by step depolarization from $-90 \mathrm{mV}$ to progressively more depolarized test potentials in the absence of Z944. Bottom, Voltage dependence of activation for voltage-gated $\mathrm{Ca}^{2+}$ currents before and after Z944 perfusion. B, top, Representative currents evoked by step depolarization to $-50 \mathrm{mV}$ after different initial test potentials. Bottom, Voltage dependence of inactivation for voltage-gated $\mathrm{Ca}^{2+} \mathrm{currents}^{2}$ 
A

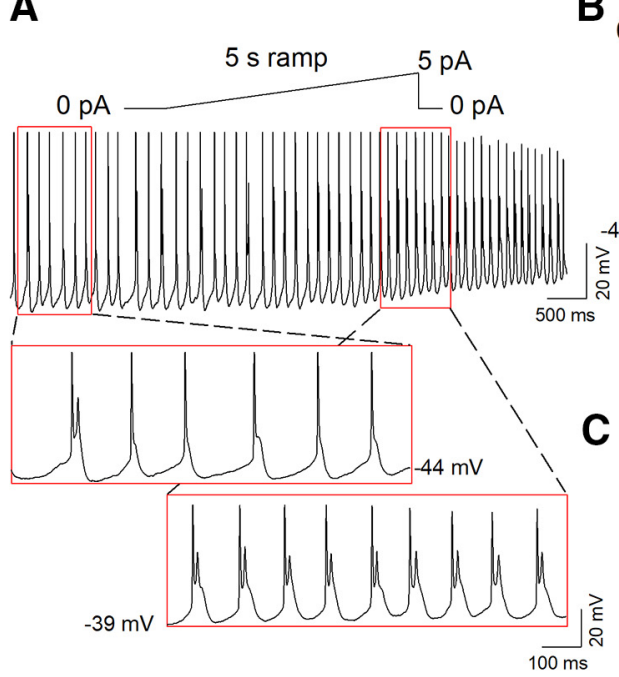

B

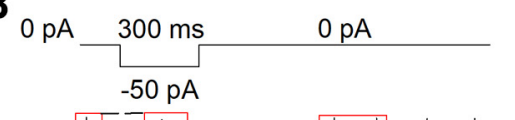

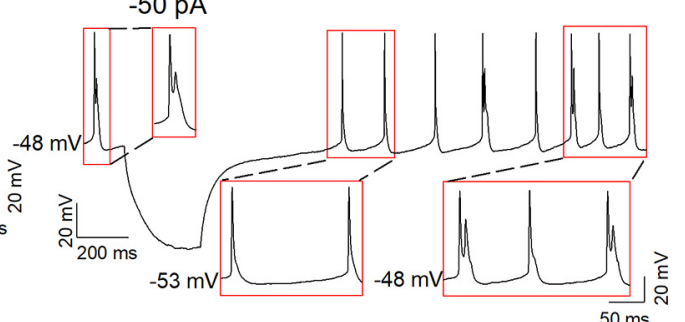

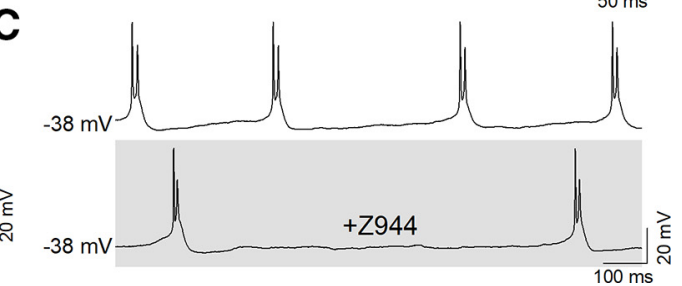

Figure 10. AP doublet firing at depolarized membrane potentials is not T-type channel mediated. $\boldsymbol{A}$, AP doublet firing at depolarized membrane potentials could be enhanced by low-level ramp depolarization. $\boldsymbol{B}$, Hyperpolarization caused a transition to tonic firing in depolarized AP doublet firing neurons, which returned to AP doublet firing on subsequent spontaneous depolarization. $\boldsymbol{C}$, Depolarized AP doublet firing was not blocked by perfusion of Z944.

displayed rebound burst firing. This bursting was observed in neurons that originally displayed all types of activity states at baseline, indicating that although T-type channel-mediated bursting is rare at resting conditions, a larger population of $\mathrm{MHb}$ neurons are capable of burst firing. Interestingly, the LHb similarly has a low percentage of spontaneously bursting neurons at baseline in Sprague Dawley rats and C57BL/6 mice, whereas congenitally learned helpless rats and mice exposed to chronic restraint stress have a substantially greater percentage of $\mathrm{LHb}$ neurons that burst at baseline (Yang et al., 2018). It is possible that the percentage of $\mathrm{MHb}$ neurons displaying different activity states may be altered in behavioral states regulated by the $\mathrm{MHb}$, such as elevated anxiety-like states or nicotine withdrawal.

We also found that some neurons burst fired during ramp depolarization but did not exhibit rebound bursting following 100 -ms or 1.5-s hyperpolarization. This is likely because depolarization following hyperpolarization is necessary for Ttype $\mathrm{Ca}^{2+}$ channel activation. Hyperpolarization-activated cyclic nucleotide-gated $(\mathrm{HCN})$ channels, in particular HCN3 and $\mathrm{HCN} 4$, are expressed in the $\mathrm{MHb}$ in rodents (Monteggia et al., 2000; Santoro et al., 2000; Notomi and Shigemoto, 2004; Görlich et al., 2013). Consistent with this, depolarizing current sag was frequently observed with 1.5-s hyperpolarization (Fig. 3D), which is a hallmark of HCN channel activation (Biel et al., 2009). It is thus likely that $\mathrm{HCN}$ channel activation can provide the rebound depolarization necessary to activate T-type $\mathrm{Ca}^{2+}$ channels in some $\mathrm{MHb}$ neurons.

In addition to burst firing from a hyperpolarized $V_{\mathrm{m}}$, some neurons displayed high-frequency AP doublet firing at depolarized potentials (average $V_{m}=-45.2 \pm 1.5 \mathrm{mV}$ ). This AP doublet firing was not affected by T-type channel blockade. This is unsurprising, as T-type channels are likely completely inactivated at these depolarized potentials. The ionic conductances mediating this depolarized burst firing remain unknown. In neurons in other brain regions, persistent $\mathrm{Na}^{+}$current can contribute to afterdepolarization and promote burst firing (Azouz et al., 1996; Brumberg et al., 2000; Su et al., 2001). It is possible that persistent $\mathrm{Na}^{+}$current or other ionic conductances mediate this depolarized burst firing.

In summary, we demonstrated that a subpopulation of $\mathrm{MHb}$ neurons are capable of high-frequency AP firing, in contrast to previous reports that $\mathrm{MHb}$ neurons solely fire tonic APs at a frequency of $\sim 2-10 \mathrm{~Hz}$. Two distinct modes of high-frequency AP firing were observed, including T-type channel-mediated bursting and T-type channel-independent AP doublets. T-type channel-mediated bursting occurred from a previously hyperpolarized $V_{\mathrm{m}}$, whereas T-type channel-independent bursting remained with sustained depolarization and was not blocked by Z944. $\mathrm{Ca}_{\mathrm{v}} 3 \mathrm{mRNA}$ was expressed in the MHb, most notably $\mathrm{Ca}_{\mathrm{v}} 3.1$ in the lateral $\mathrm{MHb}$, consistent with the predominant location of bursting $\mathrm{MHb}$ neurons. Thus, T-type $\mathrm{Ca}^{2+}$ channels may contribute to the regulation of behaviors relevant to neuropsychiatric disease by shaping the frequency and pattern of $\mathrm{MHb}$ neuron $\mathrm{AP}$ firing.

\section{References}

Agetsuma M, Aizawa H, Aoki T, Nakayama R, Takahoko M, Goto M, Sassa T, Amo R, Shiraki T, Kawakami K, Hosoya T, Higashijima S, Okamoto H (2010) The habenula is crucial for experience-dependent modification of fear responses in zebrafish. Nat Neurosci 13:1354-1356.

Antolin-Fontes B, Ables JL, Görlich A, Ibañez-Tallon I (2015) The habenulo-interpeduncular pathway in nicotine aversion and withdrawal. Neuropharmacology 96:213-222.

Arvin MC, Jin XT, Yan Y, Wang Y, Ramsey MD, Kim VJ, Beckley NA, Henry BA, Drenan RM (2019) Chronic nicotine exposure alters the neurophysiology of habenulo-interpeduncular circuitry. J Neurosci 39:4268-4281. 
Azouz R, Jensen MS, Yaari Y (1996) lonic basis of spike after-depolarization and burst generation in adult rat hippocampal CA1 pyramidal cells. J Physiol 492:211-223.

Biel M, Wahl-Schott C, Michalakis S, Zong X (2009) Hyperpolarization-activated cation channels: from genes to function. Physiol Rev 89:847-885.

Boulos LJ, Darcq E, Kieffer BL (2017) Translating the habenula-from rodents to humans. Biol Psychiatry 81:296-305.

Boulos LJ, Ben Hamida S, Bailly J, Maitra M, Ehrlich AT, Gavériaux-Ruff C, Darcq E, Kieffer BL (2020) Mu opioid receptors in the medial habenula contribute to naloxone aversion. Neuropsychopharmacology 45:247-255.

Bourinet E, Francois A, Laffray S (2016) T-type calcium channels in neuropathic pain. Pain 157 [Suppl 1]:S15-S22.

Brumberg JC, Nowak LG, McCormick DA (2000) lonic mechanisms underlying repetitive high-frequency burst firing in supragranular cortical neurons. J Neurosci 20:4829-4843.

Chang SY, Kim U (2004) lonic mechanism of long-lasting discharges of action potentials triggered by membrane hyperpolarization in the medial lateral habenula. J Neurosci 24:2172-2181.

Cheong E, Shin HS (2013) T-type Ca2 + channels in normal and abnormal brain functions. Physiol Rev 93:961-992.

Choi K, Lee Y, Lee C, Hong S, Lee S, Kang SJ, Shin KS (2016) Optogenetic activation of septal GABAergic afferents entrains neuronal firing in the medial habenula. Sci Rep 6:34800.

Cui Y, Yang Y, Ni Z, Dong Y, Cai G, Foncelle A, Ma S, Sang K, Tang S, Li Y, Shen Y, Berry H, Wu S, Hu H (2018) Astroglial Kir4.1 in the lateral habenula drives neuronal bursts in depression. Nature 554:323-327.

Fowler CD, Lu Q, Johnson PM, Marks MJ, Kenny PJ (2011) Habenular $\alpha 5$ nicotinic receptor subunit signalling controls nicotine intake. Nature 471:597-601.

Frahm S, Antolin-Fontes B, Görlich A, Zander J-F, Ahnert-Hilger G, Ibañez-Tallon I (2015) An essential role of acetylcholine-glutamate synergy at habenular synapses in nicotine dependence. Elife 4: e11396.

Ge F, Mu P, Guo R, Cai L, Liu Z, Dong Y, Huang YH (2019) Chronic sleep fragmentation enhances habenula cholinergic neural activity. Mol Psychiatry. Advance online publication. Retrieved April 12, 2019. doi:10.1038/s41380-019-0419-z.

Görlich A, Antolin-Fontes B, Ables JL, Frahm S, Slimak MA, Dougherty JD, Ibañez-Tallon I (2013) Reexposure to nicotine during withdrawal increases the pacemaking activity of cholinergic habenular neurons. Proc Natl Acad Sci USA 110:17077-17082.

Hashikawa Y, Hashikawa K, Basiri ML, Liu Y, Johnston NL, Ahmad OR, Stuber GD (2019) Transcriptional and spatial resolution of cell types in the mammalian habenula. bioRxiv. doi: https://doi.org/ 10.1101/772376.

Hsu YW, Wang SD, Wang S, Morton G, Zariwala HA, de la Iglesia $\mathrm{HO}$, Turner EE (2014) Role of the dorsal medial habenula in the regulation of voluntary activity, motor function, hedonic state, and primary reinforcement. J Neurosci 34:11366-11384.

Hsu YW, Morton G, Guy EG, Wang SD, Turner EE (2016) Dorsal medial habenula regulation of mood-related behaviors and primary reinforcement by tachykinin-expressing habenula neurons. eNeuro 3: ENEURO.0109-16.2016.

Huguenard JR, McCormick DA (2007) Thalamic synchrony and dynamic regulation of global forebrain oscillations. Trends Neurosci 30:350-356.

Joksimovic SM, Eggan P, Izumi Y, Joksimovic SL, Tesic V, Dietz RM, Orfila JE, DiGruccio MR, Herson PS, Jevtovic-Todorovic V, Zorumski CF, Todorovic SM (2017) The role of T-type calcium channels in the subiculum: to burst or not to burst? J Physiol 595:6327-6348.

Kim U, Chang SY (2005) Dendritic morphology, local circuitry, and intrinsic electrophysiology of neurons in the rat medial and lateral habenular nuclei of the epithalamus. J Comp Neurol 483:236-250.

Kim U, Chung LY (2007) Dual GABAergic synaptic response of fast excitation and slow inhibition in the medial habenula of rat epithalamus. J Neurophysiol 98:1323-1332.
Lambert RC, Bessaïh T, Crunelli V, Leresche N (2014) The many faces of T-type calcium channels. Pflugers Arch 466:415-423.

Lee A, Mathuru AS, Teh C, Kibat C, Korzh V, Penney TB, Jesuthasan $S$ (2010) The habenula prevents helpless behavior in larval zebrafish. Curr Biol 20:2211-2216.

Lisman JE (1997) Bursts as a unit of neural information: making unreliable synapses reliable. Trends Neurosci 20:38-43.

Llinás R, Jahnsen H (1982) Electrophysiology of mammalian thalamic neurones in vitro. Nature 297:406-408.

Mathuru AS, Jesuthasan S (2013) The medial habenula as a regulator of anxiety in adult zebrafish. Front Neural Circuits 7:99.

McCormick DA, Pape HC (1990) Properties of a hyperpolarizationactivated cation current and its role in rhythmic oscillation in thalamic relay neurones. J Physiol 431:291-318.

Molas S, DeGroot SR, Zhao-Shea R, Tapper AR (2017) Anxiety and nicotine dependence: emerging role of the habenulo-interpeduncular axis. Trends Pharmacol Sci 38:169-180.

Monteggia LM, Eisch AJ, Tang MD, Kaczmarek LK, Nestler EJ (2000) Cloning and localization of the hyperpolarization-activated cyclic nucleotide-gated channel family in rat brain. Brain Res Mol Brain Res 81:129-139.

Notomi T, Shigemoto R (2004) Immunohistochemical localization of Ih channel subunits, HCN1-4, in the rat brain. J Comp Neurol 471:241-276.

Otsu Y, Lecca S, Pietrajtis K, Rousseau CV, Marcaggi P, Dugué GP, Mailhes-Hamon C, Mameli M, Diana MA (2018) Functional principles of posterior septal inputs to the medial habenula. Cell Rep 22:693-705.

Perez-Reyes E (2003) Molecular physiology of low-voltage-activated t-type calcium channels. Physiol Rev 83:117-161.

Sakhi K, Belle MD, Gossan N, Delagrange P, Piggins HD (2014) Daily variation in the electrophysiological activity of mouse medial habenula neurones. J Physiol 592:587-603.

Santoro B, Chen S, Luthi A, Pavlidis P, Shumyatsky GP, Tibbs GR, Siegelbaum SA (2000) Molecular and functional heterogeneity of hyperpolarization-activated pacemaker channels in the mouse CNS. J Neurosci 20:5264-5275.

Schultz W, Dayan P, Montague PR (1997) A neural substrate of prediction and reward. Science 275:1593-1599.

Shih PY, Engle SE, Oh G, Deshpande P, Puskar NL, Lester HA, Drenan RM (2014) Differential expression and function of nicotinic acetylcholine receptors in subdivisions of medial habenula. $J$ Neurosci 34:9789-9802.

Soria-Gómez E, Busquets-Garcia A, Hu F, Mehidi A, Cannich A, Roux L, Louit I, Alonso L, Wiesner T, Georges F, Verrier D, Vincent P, Ferreira G, Luo M, Marsicano G (2015) Habenular CB1 receptors control the expression of aversive memories. Neuron 88:306313.

Stamenic TT, Todorovic SM (2018) Cytosolic ATP relieves voltagedependent inactivation of T-type calcium channels and facilitates excitability of neurons in the rat central medial thalamus. eNeuro 5: ENEURO.0016-18.2018.

Su H, Alroy G, Kirson ED, Yaari Y (2001) Extracellular calcium modulates persistent sodium current-dependent burst-firing in hippocampal pyramidal neurons. J Neurosci 21:4173-4182.

Sutherland RJ (1982) The dorsal diencephalic conduction system: a review of the anatomy and functions of the habenular complex. Neurosci Biobehav Rev 6:1-13.

Talley EM, Cribbs LL, Lee JH, Daud A, Perez-Reyes E, Bayliss DA (1999) Differential distribution of three members of a gene family encoding low voltage-activated (T-type) calcium channels. J Neurosci 19:1895-1911.

Ting JT, Lee BR, Chong P, Soler-Llavina G, Cobbs C, Koch C, Zeng $H$, Lein E (2018) Preparation of acute brain slices using an optimized N-methyl-D-glucamine protective recovery method. J Vis Exp. Advance online publication. Retrieved Feb 26, 2018. doi: 10.3791/53825.

Todorovic SM, Lingle CJ (1998) Pharmacological properties of Ttype $\mathrm{Ca} 2+$ current in adult rat sensory neurons: effects of anticonvulsant and anesthetic agents. J Neurophysiol 79:240-252. 
Tringham E, Powell KL, Cain SM, Kuplast K, Mezeyova J, Weerapura M, Eduljee C, Jiang X, Smith P, Morrison JL, Jones NC, Braine E, Rind G, Fee-Maki M, Parker D, Pajouhesh H, Parmar M, O'Brien TJ, Snutch TP (2012) T-type calcium channel blockers that attenuate thalamic burst firing and suppress absence seizures. Sci Transl Med 4:121ra119.

Tuesta LM, Chen Z, Duncan A, Fowler CD, Ishikawa M, Lee BR, Liu XA, Lu Q, Cameron M, Hayes MR, Kamenecka TM, Pletcher M, Kenny PJ (2017) GLP-1 acts on habenular avoidance circuits to control nicotine intake. Nat Neurosci 20:708-716.

van den Pol AN (2012) Neuropeptide transmission in brain circuits. Neuron 76:98-115.

Wang F, Flanagan J, Su N, Wang LC, Bui S, Nielson A, Wu X, Vo HT, Ma XJ, Luo Y (2012) RNAscope: a novel in situ RNA analysis platform for formalin-fixed, paraffin-embedded tissues. J Mol Diagn 14:22-29.

Weiss N, Zamponi GW (2020) Genetic T-type calcium channelopathies. J Med Genet 57:1-10.
Weiss T, Bernard R, Bernstein HG, Veh RW, Laube G (2018) Agmatine modulates spontaneous activity in neurons of the rat medial habenular complex-a relevant mechanism in the pathophysiology and treatment of depression? Transl Psychiatry 8:201.

Wilcox KS, Gutnick MJ, Christoph GR (1988) Electrophysiological properties of neurons in the lateral habenula nucleus: an in vitro study. J Neurophysiol 59:212-225.

Yang Y, Cui Y, Sang K, Dong Y, Ni Z, Ma S, Hu H (2018) Ketamine blocks bursting in the lateral habenula to rapidly relieve depression. Nature 554:317-322.

Zhang J, Tan L, Ren Y, Liang J, Lin R, Feng Q, Zhou J, Hu F, Ren J, Wei C, Yu T, Zhuang Y, Bettler B, Wang F, Luo M (2016) Presynaptic excitation via GABAB receptors in habenula cholinergic neurons regulates fear memory expression. Cell 166:716-728.

Zhao-Shea R, DeGroot SR, Liu L, Vallaster M, Pang X, Su Q, Gao G, Rando OJ, Martin GE, George O, Gardner PD, Tapper AR (2015) Increased CRF signalling in a ventral tegmental area-interpeduncular nucleus-medial habenula circuit induces anxiety during nicotine withdrawal. Nat Commun 6:6770. 